\title{
Adjustment for the influence of age and heart rate on Doppler measurements of left ventricular filling
}

\author{
Ralph A H Stewart, Jayshee Joshi, Neal Alexander, Petros Nihoyannopoulos, \\ Celia M Oakley
}

Department of Medicine, Hammersmith Hospital, Royal Postgraduate Medical School, London

R A H Stewart

J Joshi

P Nihoyannopoulos

C M Oakley

Department of

Medical Physics,

Hammersmith

Hospital, Royal

Postgraduate Medical

School, London

N Alexander

Correspondence to:

Dr R A H Stewart,

Cardiology Department,

Dunedin Hospital, Great

King St, Dunedin, New

King St,

Accepted for publication

9 June 1992.

\begin{abstract}
Objective-To determine the normal range of pulsed Doppler measurements of left ventricular filling adjusted for age and heart rate.
\end{abstract}

Design-Multiple regression was used to measure the effects of age and heart rate on pulsed Doppler indices of left ventricular filling in normal subjects. These regression equations were used to calculate a predicted normal value and $95 \%$ confidence interval ( $95 \% \mathrm{CI}$ ) for any subject from his age and heart rate.

Participants -61 subjects with no evidence of cardiovascular disease, aged 20 to 90 years, with a resting heart rate of 47-89 beats/min.

Results-The effect of a 10 year increase in age was peak atrial filling velocity $+15 \%(95 \%$ CI $12.0 \%$ to $18.5 \%)$; peak early filling velocity $-3 \cdot 2 \%(-6 \cdot 0 \%$ to $0 \%$ ); isovolumic relaxation time $+6.2 \%$ $(3.9 \%$ to $8 \cdot 4 \%)$; acceleration time $-3.8 \%$ $(-6.0 \%$ to $-1.5 \%)$; deceleration time $+7 \cdot 9 \%(5 \cdot 1 \%$ to $10 \cdot 8 \%)$. The effect of a 10 beat/min increase in heart rate was: peak atrial filling velocity $+5 \cdot 5 \%(1 \cdot 2 \%$ to $10 \cdot 1 \%)$; peak early filling velocity $-4 \cdot 0 \%$ $(-8 \cdot 1 \%$ to $2 \cdot 0 \%)$; isovolumic relaxation time $-2 \cdot 5 \%(-4.6 \%$ to $0 \cdot 6 \%)$; acceleration time $-3 \cdot 1 \%(-6.4 \%$ to $0 \cdot 4 \%)$; decleration time $-1 \cdot 8 \%(-4 \cdot 0 \%$ to $3 \cdot 8 \%)$.

Conclusion-For any individual, com-

The changes reported with normal aging are similar to changes reported with hypertension, ischaemia, and hypertrophy. ${ }^{12}$ Most studies have used a control group of similar age and heart rate or both when assessing changes with disease. This does not, however, allow an assessment of diastolic filling in individual patients that is independent of age and heart rate.

A method of adjusting for the influence of age and heart rate on Doppler indices of left ventricular filling is proposed.

\section{Patients and methods}

PATIENT SELECTION

Subjects had no evidence of cardiovascular disease in their history, physical examination, or cross sectional echocardiography, they were taking no medication for cardiovascular disease, and there was no evidence of infection, thyroid disease, or metabolic disturbance. All subjects older than 35 years had a normal electrocardiogram, chest $x$ ray film, urea and electrolytes, and haemoglobin. Most subjects were healthy volunteers or patients admitted to hospital for minor surgical procedures. Five subjects were excluded because Doppler studies were of poor quality. All subjects gave informed consent.

Sixty one subjects were included in the study. The mean age was 53 (SD 20.4, range 20 to 90 ) years. The mean heart rate was 68 (SD 11 , range 47 to 89 ) beats $/ \mathrm{min}$.

measuren served measurement allows an assessment of the effects of disease on left ventricular filling that is independent of age and heart rate.

(Br Heart J 1992;68:608-12)

Doppler ultrasound is a non-invasive tool that is potentially useful for assessing left ventricular diastolic function. Changes in left ventricular diastolic filling have been measured in a wide range of cardiovascular conditions. ${ }^{1-3}$ A major problem, however, is that measurements of filling vary in normal subjects with both age $e^{4-8}$ and heart rate $e^{-11}$ making interpretation of disease related changes more difficult.

\section{CROSS SECTIONAL ECHOCARDIOGRAPHY AND} DOPPLER STUDIES

Cross sectional echocardiographic and Doppler studies were performed with the Toshiba 65A imaging system. Pulsed Doppler recordings of left ventricular filling velocities were obtained from the apical four chamber view with a $2.5 \mathrm{MHz}$ transducer. The sample volume was positioned just proximal to the mitral leaflet tips with alignment adjusted to optimise the recording of flow velocity and to minimise the angle between the blood flow vector and the ultrasound beam. The flow velocity curves were recorded on videotape at $50 \mathrm{~mm} / \mathrm{s}$. Measurements were performed at a later time by an observer blind to the patient's age. 


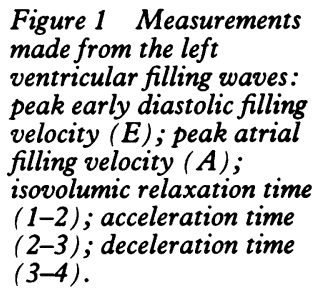
made from the left ventricular filling waves: peak early diastolic filling velocity $(E)$; peak atrial isovolumic relaxation time (1-2); acceleration time $(3-4)$.

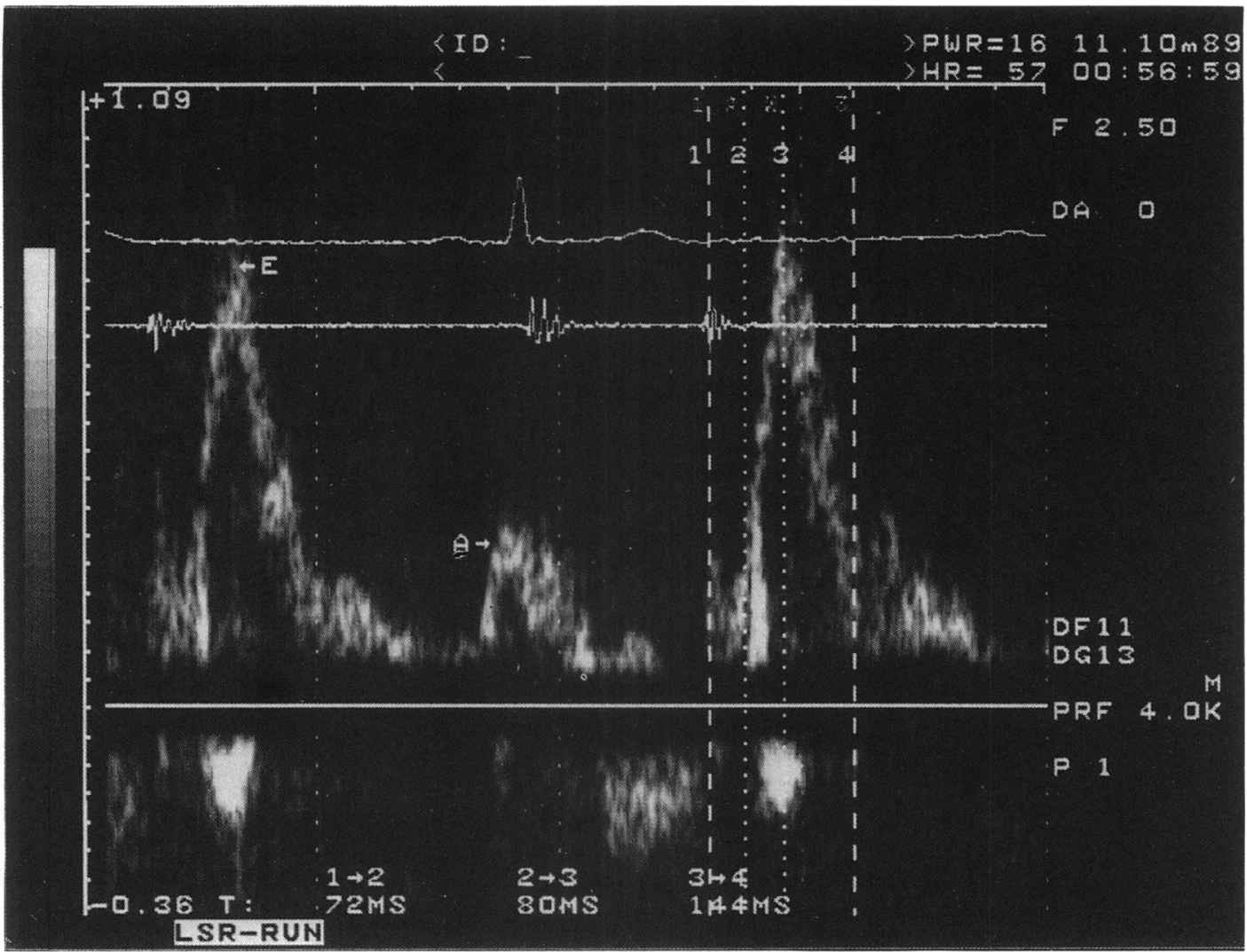

sion equations. The regression coefficient for this term was not significant $(p>0 \cdot 1)$ for any of the measurements, so this term was dropped.

The size and direction of the change in a diastolic measurement with change in age or heart rate is given by the slope of the regression line and $\mathrm{r}^{2}$, which measures the proportion of the variance explained by the regression. The $95 \%$ confidence interval $(95 \% \mathrm{CI})$ for the slope is quoted.

The predicted normal measurement can be calculated from the patient's age and heart rate in the appropriate regression equation. For each patient, the error in the prediction is the difference between the observed and the predicted values. The normal range is the range in which $95 \%$ of normal people would be predicted to lie, and was estimated as the predicted measurement within 2 SDs of this error. This simplied method of estimating the normal range is approximate. It does not take into account the increase in the width of the normal range with values of age and heart rate that are further from the mean values for the group from which the regression equations were calculated.

The normal range was also calculated by the standard method ${ }^{12}$ to see if the approximate but simplified method gives acceptably close results. The difference in the size of the normal range calculated with the two methods was determined for ages from 20 to 80 and heart rates from 50 to 85 . The greatest difference is given as a percentage and is the same for all indices.

Estimation of the normal range assumes that the spread of the real values about the regression line is constant throughout the range of ages and heart rates. This assumption was changes are expressed in percentages.

To determine whether the effect of age is influenced by the heart rate, or vice versa, a term for interaction was included in the regres- 
Table 1 Comparison of the adequacy of the regression model with absolute measurements and the natural logarithm of diastolic measurements

\begin{tabular}{|c|c|c|c|c|}
\hline \multirow[b]{2}{*}{ Diastolic measurement } & \multicolumn{2}{|c|}{$\begin{array}{l}\text { Proportion of variation (\%) explained } \\
\text { by differences in age and heart rate }\left(r^{2}\right)\end{array}$} & \multicolumn{2}{|c|}{ Non-constant variance, $p$ value } \\
\hline & Absolute & Logarithm & Absolute & Logarithm \\
\hline $\begin{array}{l}\text { Isovolumic relaxation time } \\
\text { Acceleration time } \\
\text { Deceleration time } \\
\text { Peak early filling velocity, E } \\
\text { Peak atrial filling velocity, A } \\
\text { A/E }\end{array}$ & $\begin{array}{l}36 \\
18 \\
40 \\
11 \\
69 \\
71\end{array}$ & $\begin{array}{l}36 \\
22 \\
37 \\
16 \\
69 \\
77\end{array}$ & $\begin{array}{c}<0.0001 \\
0.49 \\
<0.0001 \\
0.0003 \\
<0.0001 \\
0.072\end{array}$ & $\begin{array}{l}0.21 \\
0 \cdot 007 \\
0 \cdot 072 \\
0.0017 \\
0.98 \\
0 \cdot 48\end{array}$ \\
\hline
\end{tabular}

tested by a variant of Anscombe's test for nonconstant variance in regression. ${ }^{12}$

\section{Results}

COMPARISON OF LINEAR AND PROPORTIONAL MODELS

A similar proportion of the total variance is explained by simple regression and regression of the natural logarithm of each index for age and heart rate (table 1). The peak filling velocity during the atrial contribution $(A)$ and $\mathrm{A} / \mathrm{E}$ had the strongest association with age and heart rate, and the acceleration time and peak early diastolic filling rate had the weakest.

For the peak atrial filling velocity, the deceleration time, the isovolumic relaxation time, and $\mathrm{A} / \mathrm{E}$ the spread of values above and below the regression line increased as the predicted measurement increased. For these indices this trend for increasing spread was not significant $(p>0.05)$ if the natural logarithm was used. Conversely, for the acceleration time and peak early filling velocity the spread of values tended to decrease as the predicted value increased and this trend was not improved by taking logarithms (table 1).

Figure 2 illustrates this correlation for A, E, and the logarithm of $A$ and $E$.

\section{CALCULATION OF THE NORMAL RANGE}

To calculate the normal range by the simple method, the predicted measurement is multiplied by the values given in table 2 . The normal range is skewed because it is calculated from logarithms. The greatest increase in the size of the normal range calculated by the standard method compared with the simplified method was $5.6 \%$ at age 20 , heart rate 85 .

\section{SIZE OF AGE AND HEART RATE EFFECTS}

Table 3 summarises the effect of increasing age by 10 years and increasing heart rate by 10 beats/min in each of the diastolic measurements. The effect of age was significant for all indices $(p<0.05)$ but the effect of heart rate
Figure 2 For the peak atrial filling velocity ( $A$, measured in $\mathrm{cm} / \mathrm{s}$ ), the difference between the observed and the predicted measurements increases as the predicted measurement increases. For the natural logarithm of $A(\ln A)$ the difference between the observed and predicted measurements remains constant throughout the range of $\ln A$. The peak early diastolic filling velocity $E$ varies over a narrower range than $A$. $A$ trend for the difference between the observed and predicted values of $E$ to decrease as $E$ decreases is aggravated by taking logarithms $(\ln E)$.
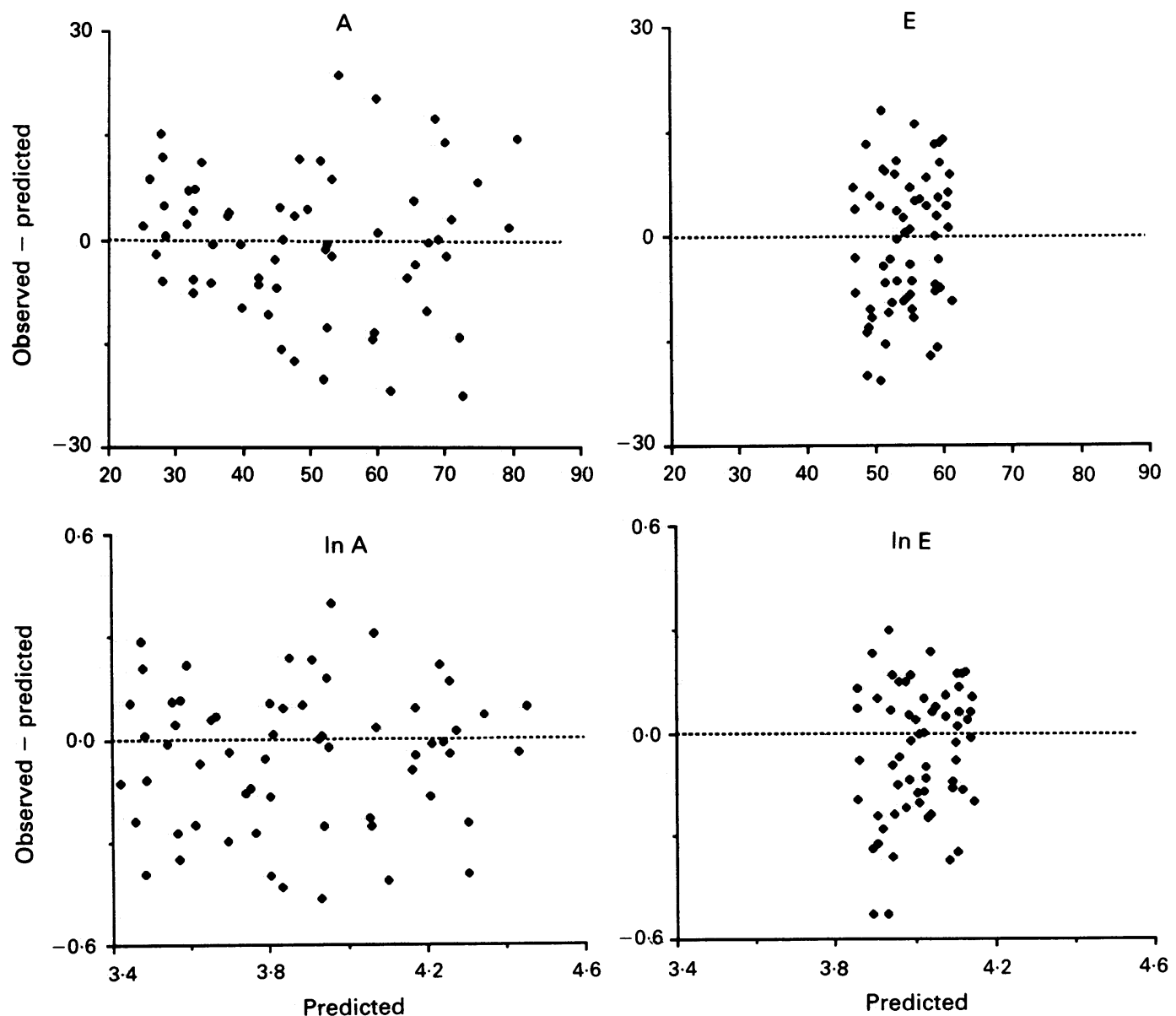
Table 2 Mean (SD) and normal range of diastolic indices

\begin{tabular}{lcll}
\hline Diastolic measurement & \multicolumn{2}{c}{$\begin{array}{l}\text { Observed measurements } \\
(\text { mean }\end{array}$} & $\begin{array}{l}95 \% \text { CI of normal values } \\
\text { about the predicted value }(z)\end{array}$ \\
\hline Isovolumic relaxation time $(\mathrm{ms})$ & 67 & $(14)$ & $0.73 \mathrm{z}$ to $1.43 \mathrm{z}$ \\
Acceleration time $(\mathrm{ms})$ & 78 & $(14)$ & $0.70 \mathrm{z}$ to $1.42 \mathrm{z}$ \\
Deceleration time $(\mathrm{ms})$ & 166 & $(42)$ & $0.68 \mathrm{z}$ to $1.48 \mathrm{z}$ \\
Peak filling rate $(\mathrm{cm} / \mathrm{s})$ & 57 & $(13)$ & $0.66 \mathrm{z}$ to $1.51 \mathrm{z}$ \\
Peak atrial filling rate $(\mathrm{cm} / \mathrm{s})$ & 51 & $(19)$ & $0.68 \mathrm{z}$ to $1.47 \mathrm{z}$ \\
A/E & $0.95(0.42)$ & $0.66 \mathrm{z}$ to $1.54 \mathrm{z}$ \\
\hline
\end{tabular}

The normal range can be estimated with the approximate method by multiplying the predicted measurement $(z)$ by the constants in the second column.

was only significant for $\mathrm{A}$ and $\mathrm{A} / \mathrm{E}$. Figure 3 shows the variation of $\ln \mathrm{A}$ with age and heart rate.

Table 4 gives the equations for the regression of the logarithm of each diastolic index incorporating age and heart rate.

\section{EXAMPLE OF ADJUSTMENT FOR AGE AND HEART RATE}

A patient with left ventricular hypertrophy is 50 years old, and the heart rate is 80 beats $/ \mathrm{min}$. $A$ is $90 \mathrm{~cm} / \mathrm{s}$. The predicted normal measurement for $\ln A$ is calculated with the equations in table 4 :

$\ln \mathrm{A}=2 \cdot 77+(0.0142 \times 50)+(0.0054 \times 80)=3.91$.

The predicted normal measurement for $\mathrm{A}$ is the exponential of $3.91=50 \mathrm{~cm} / \mathrm{s}$ and the $95 \%$ $\mathrm{CI}$ is between $34 \mathrm{~cm} / \mathrm{s}$ and $73 \mathrm{~cm} / \mathrm{s}$ (table 2). The result can also be expressed as a percentage of the predicted normal mean. In this case $\mathrm{A}$ is $180 \%$ of the predicted mean for normal subjects, with $95 \%$ of normal subjects falling within the range $68 \%$ to $147 \%$.

\section{Discussion}

With multiple regression it is possible to measure the effects of age and heart rate on left ventricular filling simultaneously and to adjust for these effects. This makes it much easier to measure the size of the effect of disease in individual subjects.

Linear regression assumes a linear relation between variables and constant variance about the regression line. For the isovolumic relaxation time, the deceleration time, and the peak atrial filling velocity, the spread of observed values increased with the size of the predicted measurement. Therefore estimation of the size of the normal range is inaccurate, as it is too large for small values and too small for large values. This problem was overcome by a logarithmic transformation that measures proportional rather than absolute changes. For the peak early filling velocity and the decelera-
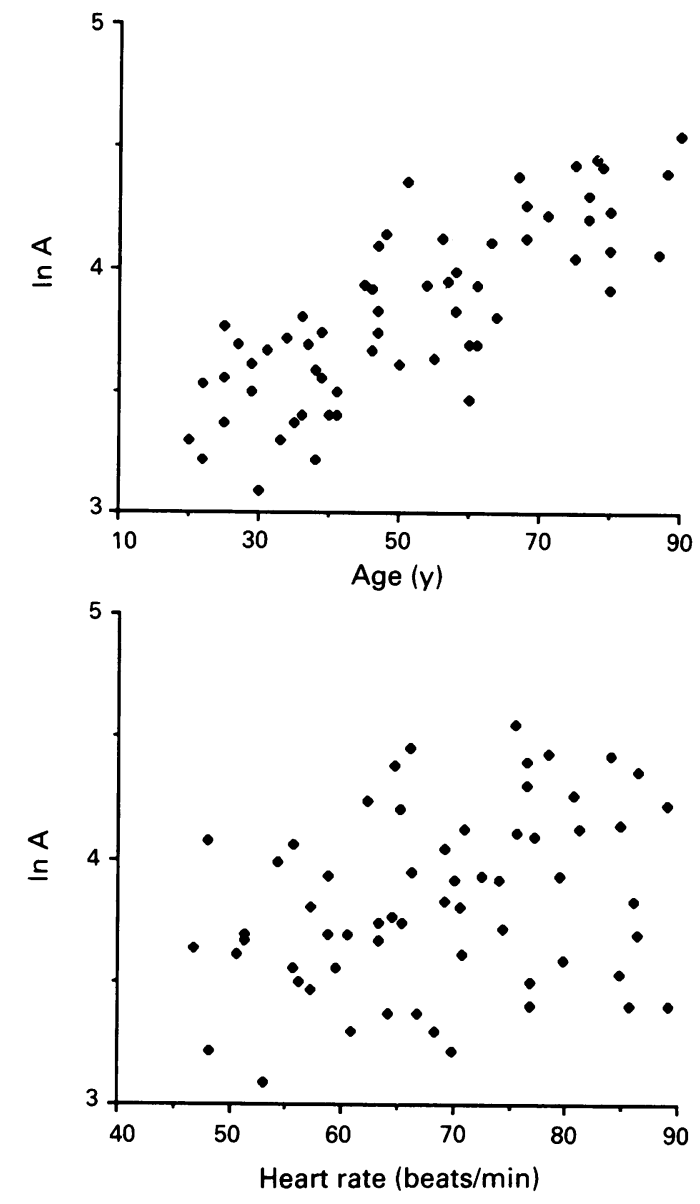

Figure 3 Relation between the natural logarithm of the peak atrial filling velocity $(\ln A)$, and age and heart rate. Ln $A$ varies more closely with age than with heart rate.

tion time non-constant variance was not improved by taking logarithms, so estimation of the normal range is less accurate. These indices were, however, much less influenced by age and heart rate, so correction for their effects may be less important.

Age had a greater effect on diastolic measurements than heart rate, and the only heat rate effect that was significant $(p<0.05)$ was on the peak atrial filling velocity. Therefore it may be reasonable to drop the heart rate correction for other indices. The relation between heart rate and left ventricular filling may change at high heart rates when the filling time is limited. In our study no subjects had a heart rate above 90 and it may be inappropriate to use the same adjustment for measurements recorded at higher heart rates. Overlap of filling waves may also influence measurements, and at present there are no clear guidelines on how to

Table 3 Influence of age and heart rate on measurements of left ventricular filling in normal subjects

\begin{tabular}{|c|c|c|c|c|}
\hline \multirow[b]{2}{*}{ Diastolic measurement } & \multicolumn{2}{|l|}{ Age } & \multicolumn{2}{|l|}{ Heart rate } \\
\hline & $\begin{array}{l}\text { Increase }(\%) \\
10 \text { years }\end{array}$ & $95 \% C I(\%)$ & $\begin{array}{l}\text { Increase }(\%) / \\
(10 \text { beats/min })\end{array}$ & $95 \% C I(\%)$ \\
\hline $\begin{array}{l}\text { Isovolumic relaxation time } \\
\text { Acceleration time } \\
\text { Deceleration time } \\
\text { Peak early filling velocity } \\
\text { Peak atrial filling velocity } \\
\text { A/E }\end{array}$ & $\begin{array}{r}6 \cdot 2^{\star} \\
-3 \cdot 8^{\star} \\
7 \cdot 9^{\star} \\
-3 \cdot 2^{\star} \\
15 \cdot 0^{\star} \\
19 \cdot 1^{\star}\end{array}$ & $\begin{array}{l}3 \cdot 9,8 \cdot 4 \\
-6 \cdot 0,-1 \cdot 5 \\
5 \cdot 1,10 \cdot 8 \\
-6 \cdot 0,0 \cdot 0 \\
12 \cdot 0,18 \cdot 5 \\
15 \cdot 8,22 \cdot 5\end{array}$ & $\begin{array}{l}-2 \cdot 5 \\
-3 \cdot 1 \\
-1 \cdot 8 \\
-4 \cdot 0 \\
5 \cdot 5^{\star} \\
9 \cdot 9^{\star}\end{array}$ & $\begin{array}{l}-4 \cdot 6,0 \cdot 6 \\
-6 \cdot 4,0 \cdot 4 \\
-4 \cdot 0,3 \cdot 8 \\
-8 \cdot 1,2 \cdot 0 \\
1 \cdot 2,10 \cdot 1 \\
4 \cdot 5,15 \cdot 6\end{array}$ \\
\hline
\end{tabular}

Results are based on the regression of the natural logarithm of each index on age and heart rate. ${ }^{\star} \mathrm{p}<0.05$. 
Table 4 Equations for calculating the predicted normal value of each diastolic index from the subjects age and heart rate

\begin{tabular}{llcl}
\hline ln index & $a$ & $b 1$ & $b 2$ \\
\hline In IVRT & $(\times$ age $(y))$ & $(\times$ heart rate (beats $/$ min $))$ \\
In acceleration time & 4.05 & 0.006 & -0.0026 \\
In deceleration time & 4.75 & -0.0039 & -0.0031 \\
$\ln \mathrm{E}$ & 4.69 & 0.0076 & -0.002 \\
$\ln \mathrm{A}$ & 4.47 & -0.0033 & -0.0042 \\
$\ln \mathrm{A} / \mathrm{E}$ & 2.77 & 0.0142 & 0.0054 \\
& -1.7 & 0.0175 & 0.0095 \\
\hline
\end{tabular}

Equations for regression of the natural logarithm (ln) of diastolic indices on age and heart rate. $\ln$ (index) $=\mathrm{a}+\mathrm{b} 1$ (age) $+\mathrm{b} 2$ (heart rate). IVRT, isovolumic relaxation time, $\mathrm{E}$, peak filling rate; $A$, peak atrial filling rate; $\ln$, natural logarithm.

adjust for this. Measuring the effect of between subject differences in heart rate during a standard Doppler study has some advantages over measuring the effects of interventions such as atrial pacing ${ }^{11}$ or the cold pressor test. ${ }^{9}$ These interventions may be associated with different changes in left ventricular filling depending on how the intervention influences cardiac output, contractility, and relaxation.

Several factors other than age and heart rate are known to influence filling in normal subjects. Variation with respiration ${ }^{13}$ can be minimised by performing the recordings during quiet respiration and taking the mean of several measurements. The influence of blood pressure and left ventricular hypertrophy in normal subjects are at least partly explained by differences in age. ${ }^{48}$ Differences in preload, which occur with changes in position may be important. ${ }^{14}{ }^{15}$ On the other hand studies have shown that Doppler indices of filling are not influenced by sex, ${ }^{816}$ body surface area, ${ }^{416}$ or an increase in left ventricular mass associated with athletic training. ${ }^{17}$

The relations between a diastolic index, age, and heart rate are almost certainly altered in patients with abnormal diastolic filling. ${ }^{1819}$ Keucherer et al showed that the relation between age and the A:E ratio measured by Doppler was different in patients with coronary artery disease. ${ }^{18}$ Disease effects are of unknown size, vary between patients, and occur on top of age and heart rate effects. A practical approach is to measure the difference in filling from the measurement expected for the subject's age and heart rate.

Occult coronary artery disease may be present in some of the subjects studied. This disadvantage was accepted to obtain a large study population across a wide range of ages. Coronary artery disease in symptom free patients taking no treatment has not been shown to influence left ventricular filling.

The calculations can be done simply with a pocket calculator. The formulas used, however, to adjust for age and heart rate and the normal ranges for measurements depend on a standard technique. Filling measurements are influenced by sampling position, ${ }^{20}$ and adjustment for measurements made at the mitral annulus would be different.

The calculation of a predicted normal value and a normal range for measurements of diastolic filling allows a more accurate assessment of the effects of disease on left ventricular filling in individual patients.

This study was supported by a grant from Nissan UK Ltd.

1 Spirito P, Maron BJ. Doppler echocardiography for assessing left ventricular diastolic function. Ann Intern Med 1988;109:122-6.

2 Harizi RC, Bianco JA, Alpert JS. Diastolic function of the heart in clinical cardiology. Archives of Internal Medicine 1988;148:99-109.

3 Appleton CP, Hatle LK, Popp RL. Relation of transmitral flow velocity patterns to left ventricular diastolic function: new insights from a combined haemodynamic and Doppler echocardiographic study. J Am Coll Cardiol Doppler echocardi

4 Van Dam I, Fast J, De Boo T, Van Oort A, Heringa A, Alsters J, et al. Normal diastolic filling pattens of the left ventricle. European Journal of Cardiology 1988;9:165-71.

5 Bryg RJ, Williams GA, Labovitz AJ. Effect of aging on left ventricular diastolic filling in normal subjects. Am J Cardiol 1987;59:971-4.

6 Miller TM, Grossman WT, Schectman KB, et al. Left ventricular diastolic filling and its association with age. $\mathrm{Am}$ $J$ Cardiol 1986;58:531-5.

7 Miyatake K, Okamoto M, Kinoshita N, et al. Augmentation of atrial contribution to left ventricular inflow with aging as assessed by intracardiac Doppler flowmetry. Am J Cardiol 1984;53:586-9.

8 Spirito P, Maron BJ. Influence of aging on Doppler echocardiographic indices of left ventricular diastolic function. Br Heart J 1988;59:672-9.

9 Smith SA, Stoner JE, Russell AE, Sheppard JM, Aylward PE. Transmitral velocities measured by pulsed Doppler in healthy volunteers: effects of acute changes in blood healthy volunteers: effects of acute changes in

10 Bianco JA, Filiberti AW, King MA, et al. Ejection fraction and heart rate correlate with peak filling rate at rest and and heart rate correlate with peak filling
during exercise. Chest 1985;88:107-13.

11 Lavine SJ, Krishnaswami V, Levinson N, Shaver JA. Effect of heart rate alterations produced by atrial pacing on the pattern of diastolic filling in normal subjects. Am J Cardio 1989;62:1098-102.

12 Wetherill GB. Regression analysis with applications. London Chapman and Hall, 1986:223.

13 Uiterwaal C, Van Dam I, De Boo Th, Van Keulen P, Folgering $\mathrm{H}$, Hopman J, Daniels $\mathrm{O}$. The effect of respiration on diastolic flow velocities in the human heart. Eur Heart $J$ 1989;10:108-12.

14 Wallmeyer K, Wann LS, Sagar KB, et al. The influence of preload and heart rate on Doppler echocardiographic indexes of left ventricular performance: comparison with invasive indexes in an experimental preparation. Circulation 1986;74:181-6.

15 Plotnick GD, Kahn B, Rogers WJ, Fisher ML, Becker LC Effect of postural changes, nitroglycerin and verapamil on diastolic ventricular function as determined by radionudiastolic ventricular function as determined by radionu-
clide angiography in normal subjects. J Am Coll Cardio clide angiography

16 Gardin JM, Rohan MK, Davidson DM, et al. Doppler transmitral flow velocity parameters: relationship between age, body surface area, blood pressure and gender in normal subjects. American Journal of noninvasive Cardiology 1987;1:3-10.

17 Finkelhor RS, Hanak LJ, Bahler RC. Left ventricular filling in endurance trained subjects. J Am Coll Cardiol 1986, 58:289-93.

18 Kuecherer H, Ruffmann K, Kuebler W. Effect of aging on Doppler echocardiographic filling parameters in norma subjects and in patients with coronary artery disease. Clin Cardiol 1988;11:303-6.

19 Kuo LC, Quinones MA, Rokey R, et al. Quantification of atrial contribution to left ventricular filling by pulsed Doppler echocardiography and the effect of age in normal and diseased hearts. Am J Cardiol 1987;59:1174-8.

20 Jaffe WM, Dewhurst TA, Otto CM, Pearlman AS. Influence of Doppler sample volume location on ventricular filling velocities. Am J Cardiol 1991;68:550-2. 